\title{
Current Dental Research Journal
}

\section{Evaluation of the Effect of Two Commercially Available Non-Alcoholic Mouthrinses on the Microhardness of Composite Material- an in Vitro Study}

\author{
RESHMA RAJASEKHAR ${ }^{*}$, BABY JAMES, \\ MINIMOL K JOHNY and JOSE JACOB \\ Department of Conservative Dentistry and Endodontics, Pushpagiri \\ College of Dental Sciences, Thiruvalla, Kerala, India.
}

\begin{abstract}
Background; Composites have been widely used for anterior as well as posterior restorations due to increased aesthetic demands. Composite restorations placed in patients oral cavity is subjected to masticatory load, $\mathrm{pH}$ changes and chemical effect due to mouth washes, beverages, food etc. and the detrimental effects associated with these challenges on the micro hardness of composite has to be determined. The study was conducted to evaluate the effect of two commercially available non-alcoholic mouth rinses on the micro hardness of microhybrid and nanohybrid composite resins.

Materials and Methods: Forty disc shaped composite specimens were made from each type of composite materials and were divided into 5 groups with 8 samples each, Group 1= Microhybrid+Chlorhex, Group2=Microhybrid+Hexidine, Group3= Nanohybrid+Chlorhex , Group4= Nanohybrid+Hexidine, Group $5=$ Nanohybrid and Microhybrid + artificial saliva (Control). The samples were immersed in mouthrinses for $24 \mathrm{hrs}$ and micro hardness was subsequently measured using a Vicker's micro hardness tester.

Results: There was no significant difference in micro hardness values of tested composite resins in either mouthrinses, when compared to composites immersed in artificial saliva.

Conclusion: Non-alcoholic mouth rinses do not affect the micro hardness of microhybrid and nanohybrid composites.
\end{abstract}

CONTACT Reshma Rajasekhar \reshmarajasekhar@gmail.com 9 Department of Conservative Dentistry and Endodontics,Pushpagiri College of Dental Sciences, Thiruvalla, Kerala, India.

\section{(c) (i)}

(C) 2019 The Author(s). Published by Enviro Research Publishers.

This is an 2 Open Access article licensed under a Creative Commons license: Attribution 4.0 International (CC-BY).

Doi: https://doi.org/10.12944/EDJ.01.01.03 


\section{Introduction}

Tooth coloured restorations have been widely used in dentistry due to increased aesthetic demands. It is important that the restorative material within the patients oral cavity should be having sufficient physical and mechanical property. Different types of tooth coloured restorative materials with varying physical and mechanical properties are available. Among them composite materials have been primarily used for anterior and posterior restorations.

The composition of composites has evolved significantly since its introduction more than 50 years ago. The most important changes have been in the size and amount of filler particles, which have dramatically affected the physical and aesthetic properties of the composites. ${ }^{1}$

Composite restorations once placed in patients mouth are subjected to various oral environmental challenges such as masticatory forces, saliva, varying $\mathrm{pH}$ conditions due to consumption of drinks, mouthwashes containing different chemicals, beverages and foods that are likely to stain the composite, thermal changes, and stresses from parafunctional habits like bruxism. Therefore it is crucial that the composite restorations used, have to be able to withstand the complex environmental conditions within the oral cavity.

Mouthwashes have been widely used for the purpose of preventing caries and periodontal diseases and are considered as a valuable adjunct to mechanical methods for controlling plaque and gingivitis. ${ }^{2}$ Commercially available mouth rinses consist of water, antimicrobial agents, salts, preservatives and, in some cases, alcohol. Alcohol in mouth rinses is used primarily as a solvent, taste enhancer, and antiseptic agent. The variation in the concentration of these constituents will affect the $\mathrm{pH}$ of the mouth rinse. ${ }^{3}$

Chlorhexidine mouth rinses are considered the gold standard among mouthwashes and possess

Table1: Composition of the materials used in the study

\begin{tabular}{|c|c|}
\hline Materials used & Composition \\
\hline Hexidine (ICPA Health products Ltd, India) & $\begin{array}{l}0.2 \% \text { w/v chlorhexidine gluconate } \\
\mathrm{pH}-5.6\end{array}$ \\
\hline Chlorhex (Dr. Reddy's,India) & $\begin{array}{l}0.2 \% \text { w/v chlorhexidine gluconate } \\
\mathrm{pH}-5.9\end{array}$ \\
\hline Artificial saliva & $\begin{array}{lc}\mathrm{CaCl}_{2} & -0.103 \mathrm{~g} / \mathrm{L}, \\
\mathrm{MgCl}_{2} \cdot 6 \mathrm{H}_{2} \mathrm{O} & -0.019 \mathrm{~g} / \mathrm{L} \\
\mathrm{KH}_{2} \mathrm{PO}_{4} & -0.544 \mathrm{~g} / \mathrm{L} \\
\mathrm{KCl} & -2.24 \mathrm{~g} / \mathrm{L} \\
\mathrm{HEPES} \text { buffer acid- } 4.77 \mathrm{~g} / \mathrm{L} \\
\mathrm{KOH} \text { adjusted to } \mathrm{pH} 7.0\end{array}$ \\
\hline Charisma Smile (Heraeus Kulzer) & $\begin{array}{l}\text {-BisGMA } \\
\text {-TEGDMA } \\
\text {-Camphorquinone } \\
\text {-Ba-Al-B-F-Si Glass- } 78 \% \text { by wt } \\
\text {-Pyrogenic } \mathrm{SiO}_{2}\end{array}$ \\
\hline Tetric N Ceram (Ivoclar Vivadent) & $\begin{array}{l}\text {-UDMA, Bis-GMA } \\
\text {-TEGDMA } \\
\text {-Ethoxylated Bis-EMA } \\
\text {-Barium glass, ytterbium trifluoride } \\
\text { mixed oxide, } \mathrm{SiO}_{2}-63.5 \% \\
\text {-Prepolymers- } 17 \% \\
\text {-Additives, stabilizers, catalysts, } \\
\text { pigments }\end{array}$ \\
\hline
\end{tabular}


broad antimicrobial action because of its dicationic nature and its substantivity. It has been reported that mouth rinses can affect the physical and mechanical properties of composite, especially because of its $\mathrm{pH}$ and alcohol content. Surface hardness is the resistance of the composite material to indentation or penetration, and this property is significantly affected by alcoholic mouthrinses. Hardness of a material contributes to its wear resistance and its ability to abrade or be abraded by dental structures and other materials. ${ }^{4}$

It has been revealed that alcohol is a good dimethacrylate solvent. Alcohol can soften the matrix of composites by increasing the amount of unreacted monomers and oligomers that diffuse out of the material. ${ }^{5,6}$

The most popular composite material currently used by dental practitioners are microhybrid and nanohybrid composites. With the introduction of the concept of nanotechnology in dentistry, termed nanodentistry in 2000 by R.A. Freitas Jr. there has been a surge in research for exploring the potential of different nanomaterials for dental uses. ${ }^{7}$ With this concept in mind, nanocomposites with nanosized filler particles have been developed. These nanocomposites have higher filler content which results in many advantages such as reduced polymerization shrinkage, improved physical properties, and higher polishability. ${ }^{8}$

Thus there has been a remarkable improvement in the mechanical, physical and aesthetic properties of composites used nowadays. The effect of different types of commercial alcoholic mouthwashes on its mechanical and esthetic properties have been

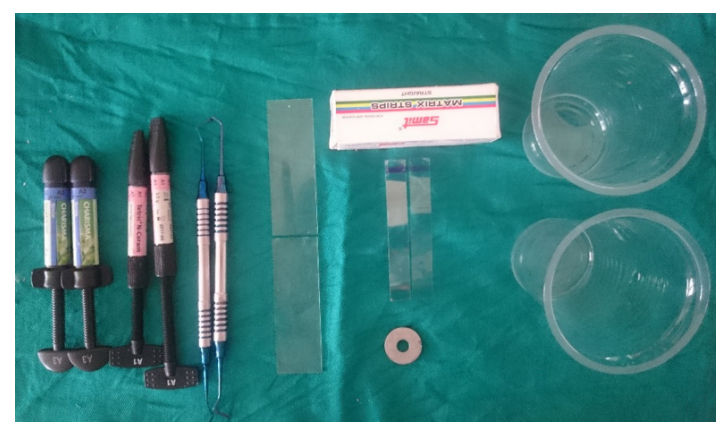

Fig. 1: Materials used in the study studied showing the detrimental effect of alcohol content on the micro hardness. There are variety of non-alcoholic mouth rinses available on market and the studies on its effect on micro hardness of composite material is limited. Thus in this study we are evaluating the effect of two commercially available non alcoholic mouth rinses on the micro hardness of composite material.

\section{Materials and Methods}

40 disc shaped composite specimens of dimension $7 \times 2 \mathrm{~mm}$ thickness were prepared using metal mould. 20 specimens made from microhybrid (Charisma Smile, Heraeus Kulzer) and the remaining 20 specimens made from nanohybrid (Tetric $\mathrm{N}$ ceram, Ivoclar vivadent). A stainless steel mould was placed over a mylar strip(Samit, India), which was then positioned over a microscopic glass slide (Borosil, India). The composite material was inserted into the mould with the aid of a teflon coated composite filling instrument (GDC, India). A mylar strip was placed over the uncured composite, followed by a glass slide on top. Pressure was applied on both sides of the disks to form a flat surface, and then light cured for 20 seconds (Bluephase N M, Ivoclar Vivadent). After curing, the composite discs were immersed in distilled water (Zydus Cadilla, India) for $24 \mathrm{hrs}$, followed by polishing using soflex discs. (3M-ESPE Dental Products, St. Paul, MN, USA)

The samples were divided in to 5 groups based on the composite material and the type of mouth rinse used for immersion.

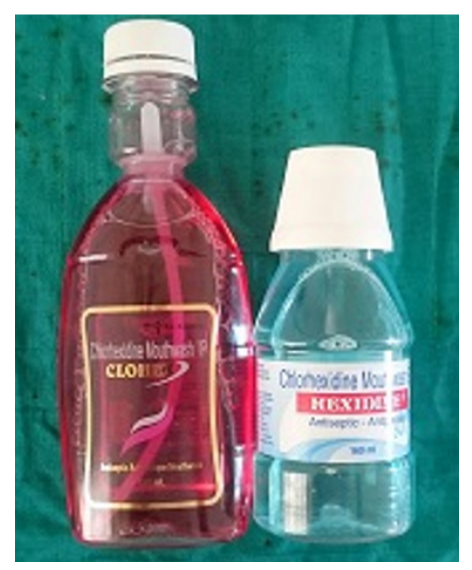

Fig. 2: Chlorhex and Hexidine mouthwash 
These specimens were immersed into $20 \mathrm{ml}$ of non-alcoholic mouth rinses for $24 \mathrm{hrs}$. Micro hardness of the specimens were measured using Vickers micro hardness tester (Shimadzu HMV-2TAW). An average of 5 areas were indented per sample with a test load of $50 \mathrm{~g}$ force for 14 secs and the mean values were obtained. The average microhardness values per group were expressed as mean \pm standard deviation as shown in Table 3. Inter group comparison done with Kruskal-Wallis test followed by Mann-Whitney U test used with SPSS version 19. $p<0.05$ were considered to be significant.

Statistical analysis of the data demonstrated no significant difference in micro hardness values between the microhybrid composite immersed in chlorhex $(p=0.328)$ ( Group 1) \& hexidine $(p=0.461)$ (Group 2) in comparison to the control group. There was no significant difference between the nanohybrid composite immersed in chlorhex $(\mathrm{p}=0.57)$ (Group 3)\& hexidine ( $p=0.99)$ (Group 4) relative to the control group. Interestingly, no significant

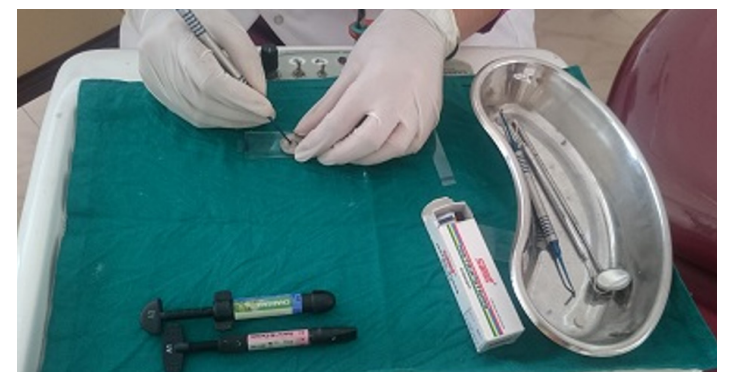

Fig. 3: Placement of composite resin into the mold difference was observed in micro hardness between nanohybrid and microhybrid composites immersed in hexidine. $(p=0.328)$ (Group $2 \& 4)$. Data showed no significant difference comparing nanohybrid and microhybrid composite immersed in chlorhexidine. $(p=0.721)$ (Group $1 \& 3$ ). Fig 6 illustrating the comparison of the micro hardness values of the six groups.

\section{Discussion}

Superior aesthetics and excellent clinical durability for the tooth coloured restorations are the prime reasons driving the current global demand for esthetic restorative materials. Several microhybrid and nanohybrid composites have been introduced which has reported efficacy sufficient to be used in oral cavity. Within the oral cavity, these restorative materials are subjected to various challenges every day as a result of masticatory forces, such as change in $\mathrm{pH}$ due to consumption of different beverages, frequent use of commercial mouthwashes, temperature changes, and actions of cariogenic bacteria.

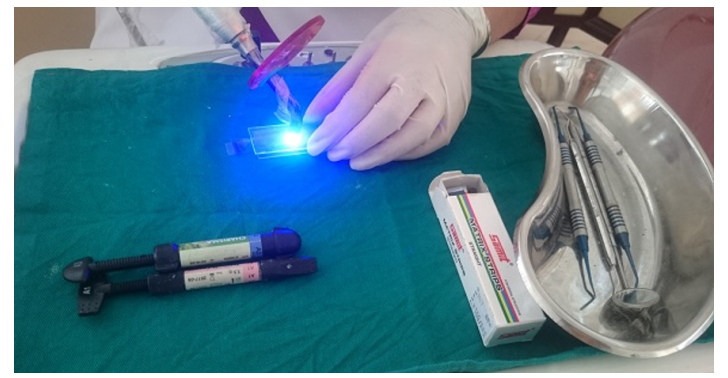

Fig. 4: Lightcuring the composite after placement of glass slide over the mold

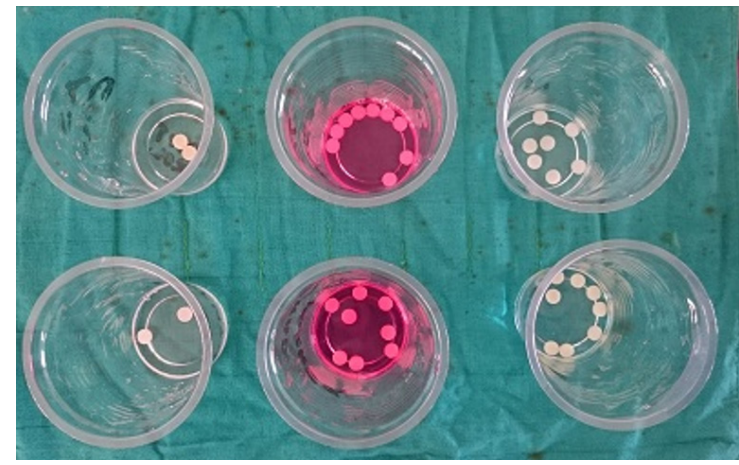

Fig. 5: Composite samples immersed in mouth rinse 
Therefore apart from invitro studies focussing on mechanical and aesthetic properties alone, the effect of these challenges on composite materials needs to be studied and various studies have been reported. Among them the action of mouth rinses on composites have been examined, with more focus given on alcohol containing mouth rinses. There are studies showing the effect of different commercial mouth rinses on the micro hardness, surface roughness, sorption, colour stability of different composite materials. It has been shown that alcohol can reduce the surface hardness of composites. $^{2,}$, 10 Hardness is defined as material's resistance to indentation or penetration. Hardness of a material can affect the clinical durability of a restoration. ${ }^{11}$ Therefore, a decrease in the hardness of a material can result in premature failure of a restoration which will lead to further replacement of restoration. Researches on the effect of nonalcoholic mouth rinses on the micro hardness of composite materials are limited, which is the focus of this study.

Chlorhexidine is used in this study since it is considered as the gold standard mouthrinse against which all other mouth rinses are compared. Chlorhexidine digluconate has been found to be very effective in prevention as well as control of plaque formation, and inhibiting and preventing the development of gingivitis. The binding property of the $\mathrm{CHX}$ molecule result in a broad bactericidal and bacteriostatic mode of action and possess high substantivity up to 12 hours within oral cavity. ${ }^{12}$ Clinically, the patients were advised to use chlorhexidine mouth wash one minute for two to three times per day. Therefore, in this study, the specimens were immersed in chlorhexidine and artificial saliva for $24 \mathrm{~h}$, which is equivalent to a minimum of 2 years

Table 2: Study groups

\begin{tabular}{ll}
\hline Groups & \\
\hline Group 1 & Microhybrid(8)+Chlorhex \\
Group 2 & Microhybrid(8)+Hexidine \\
Group 3 & Nanohybrid(8)+Cholrhex \\
Group 4 & Nanohybrid(8)+Hexidine \\
Group 5 & Artificial saliva + Microhybrid(4) \\
& Artificial saliva + Nanohybrid(4) \\
\hline
\end{tabular}

of 2 min use according to El-Badrawy et al., in 1993. ${ }^{13}$ In the present study, we have evaluated the efficacy of commercially available non alcohol mouth rinses, Hexidine and Chlorhex against microhybrid and nanohybrid composites, and found that these mouth rinses did not reduce the micro hardness values of the composite resins.

This result is in agreement with the findings of Abo et al., in 2012, ${ }^{14}$ Rios et al., in 2008, ${ }^{15}$ Gurdal et al,. in 2002. ${ }^{16}$ Abo et al., in 2012 evaluated the efficacy of chlorhexidine mouth rinse on the micro-hardness and surface roughness on nanoionomer, nano ceramic composite and giomer and they found that exposure to chlorhexidine increased the surface roughness of the three materials more than storage in artificial saliva, and had no effect on the microhardness. Devallo et al., in 2016 evaluated the effect of non-alcoholic mouth rinses on microhybrid composite resin and found that mouth rinses had no effect on the microhardness of composite. Rios et al.,(2008) found that, there were no differences in micro hardness among the restorative materials and between the saliva and the erosive challenge. Gurdal et al.,(2002) found that there were no significant adverse effect of the mouth washes on micro hardness of restorative resins.

Miranda et al., (2011), ${ }^{2}$ Pengugonda et al.,(1994) ${ }^{6}$ and Weiner et al., (1994) ${ }^{17}$ found that alcohol or hydrogen peroxide containing mouthwashes can reduce the hardness of composite. According to Asmussen in 1984, the authors demonstrated that ethanol can soften BIS-GMA based polymers. ${ }^{5}$ This softening effect is proportional to the amount of alcohol present in the mouth rinses. ${ }^{6}$

Table 3: Mean and standard deviation values

\begin{tabular}{lll}
\hline Groups & $\begin{array}{r}\text { Mean } \\
\end{array}$ & $\begin{array}{c}\text { Standard } \\
\text { deviation }\end{array}$ \\
\hline Group 1 (Microhybrid + Chlorhex) & 53.3 & 1.64 \\
Group 2 (Microhybrid + Hexidine) & 52.4 & 1.54 \\
Group 3 (Nanohybrid + Chlorhex) & 58.2 & 0.89 \\
Group 4 (Nanohybrid + Hexidine) & 57.4 & 1.83 \\
Group 5 (Artificial saliva + Microhybrid) & 55.9 & 1.95 \\
(Artificial saliva +Nanohybrid) & 59.3 & 2.11 \\
\hline
\end{tabular}


Alcohol can penetrate into the polymer and cause the release of unreacted monomers which will result in damage to the polymer chain. The low $\mathrm{pH}$ of alcohol containing mouth rinses catalyses the ester groups from dimethacrylate monomers present in the composite. This is followed by hydrolytic degradation of the composite material. ${ }^{16}$

However Gürgan, et al., (1997) ${ }^{16}$ showed both alcohol-containing and alcohol-free mouth rinse solutions affected the properties of composite resins. In the study of Gurgan et al., (1997), following the finishing and polishing of composite material they were immersed in distilled water to complete post-irradiation polymerization. But in our study, the finishing and polishing were completed after 24 hrs storage of samples in water. According to Yap et al., in 1998, ${ }^{19}$ because of the difference between filler and matrix hardness immediately after light curing, finishing and polishing performed immediately will lead to loss of matrix phase preferentially than filler particles. Curing reaction of the photopolymerized composite resins continue for a period of $24 \mathrm{hrs}$, thus early finishing polishing procedures can increase the susceptibility of the resins to heat, resulting in reduction of surface hardness.

The literature is still controversial about the influence of mouthwashes on the mechanical and physical properties of composites. There are varying reports showing no adverse effect of alcohol containing mouth rinses on the hardness of the composite material and claimed that micro hardness is material dependent rather than the rinsing solutions used..$^{20,21}$

It has been found that the use of mouth rinses with high alcohol content increases the risk of oropharyngeal cancer. ${ }^{22}$ Alcohol-free mouth rinses cause less pain to patients, than those containing alcohol. ${ }^{23}$ If the percentage of alcohol in the mouth rinse is $>25 \%$ it may be implicated for oral carcinoma. Alcohol-free mouth rinses have been shown to be as effective as alcohol-containing ones and more effective than placebo solutions in prevention and control of plaque and gingivits. ${ }^{24,25}$

The limitation of this study is that the in vivo oral conditions are different from in vitro experimental conditions. Several other factors need to be taken into consideration, such as saliva which may dilute or buffer the mouth rinse, salivary pellicle that might have a protective effect, food habits, beverages, temperature changes and change in $\mathrm{pH}$, oral care products, which may isolate and interfere with the physical and mechanical properties of the materials, influencing the durability of the restorative treatment. Therefore, further studies are necessary to determine the effects of mouthrinses in vivo.

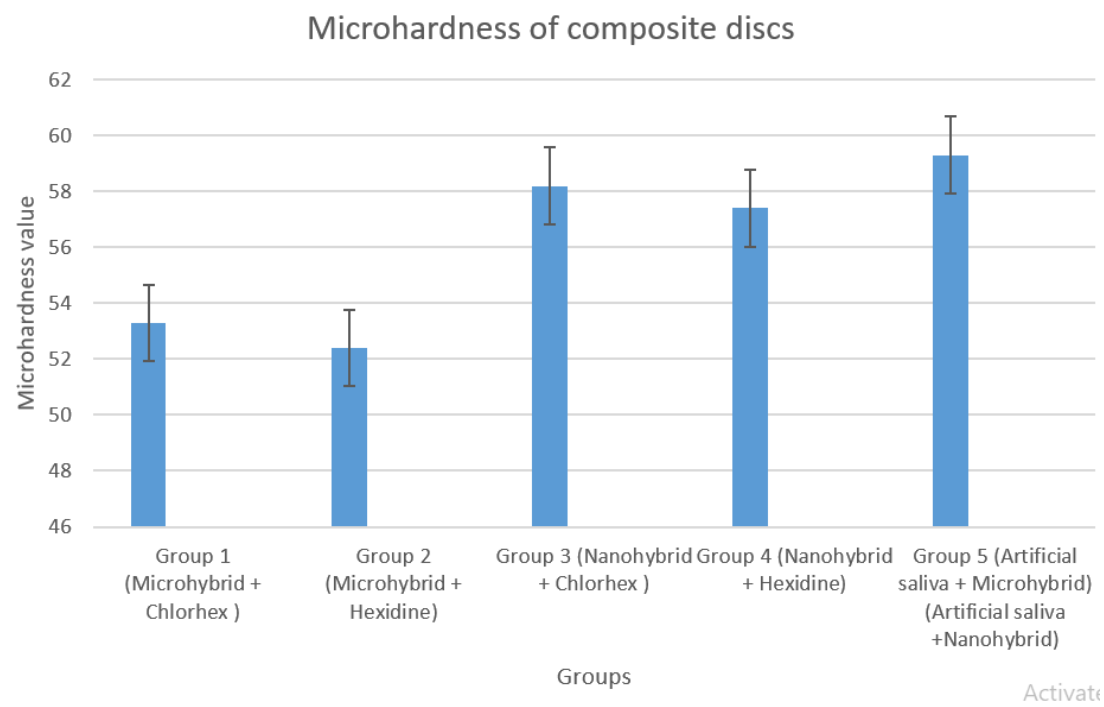

Fig. 6: Graph showing microhardness of composite discs 


\section{Conclusion}

There is no reduction in micro hardness values of microhybrid and nanohybrid composite when immersed in non-alcoholic mouth rinses, compared to composites immersed in artificial saliva as control.

\section{Acknowledgement}

I thank Prof. Dr. Baby James, Dr.Minimol K. Johny and Prof. Dr. Jose Jacob for their guidance and support in finishing my research. There was no source of financial support.

\section{References}

1. Ferracane JL. Resin composite-state of the art. Dent Mater. 2011;27(1):29-38.

2. Miranda D de A, Bertoldo CE dos S, Aguiar FHB, Lima DANL, Lovadino JR. Effects of mouthwashes on Knoop hardness and surface roughness of dental composites after different immersion times. Braz Oral Res. 2011;25(2):168-173.

3. Almeida GS, Poskus LT, Guimarães JGA, Silva EM. The effect of mouthrinses on salivary sorption, solubility and surface degradation of a nanofilled and a hybrid resin composite. Oper Dent. 2010;35(1):105-111.

4. Fernandez RAA, El Araby M, Siblini M, Al-Shehri A. The effect of different types of oral mouth rinses on the hardness of Silorane-based and Nano-hybrid composites. Saudi J Oral Sci. 2014;1(2):105.

5. Asmussen E. Softening of BISGMA-based polymers by ethanol and by organic acids of plaque. Eur J Oral Sci. 1984;92(3):257-261.

6. Penugonda B, Settembrini L, Scherer W, Hittelman E, Strassler H. Alcohol-containing mouthwashes: effect on composite hardness. J Clin Dent. 1994;5(2):60-62.

7. Freitas Jr RA. Nanodentistry. J Am Dent Assoc. 2000;131(11):1559-1565.

8. Mitra SB, Wu D, Holmes BN. An application of nanotechnology in advanced dental materials. J Am Dent Assoc. 2003;134(10):1382-1390.

9. Gürgan $S$, Önen $A$, Köprülü $H$. In vitro effects of alcohol-containing and alcohol-free mouthrinses on microhardness of some restorative materials. J Oral Rehabil. 1997;24(3):244-246.

10. Kao EC. Influence of food-simulating solvents on resin composites and glass-ionomer restorative cement. Dent Mater. 1989;5(3):201-208.
11. Anusavice KJ, Shen C, Rawls HR. Phillips' science of dental materials. Elsevier Health Sciences; 2013.

12. Van Strydonck DA, Slot DE, Van der Velden U, Van der Weijden F. Effect of a chlorhexidine mouthrinse on plaque, gingival inflammation and staining in gingivitis patients: a systematic review. J Clin Periodontol. 2012;39(11):1042-1055.

13. El-Badrawy WAG, McComb D, Wood RE. Effect of home-use fluoride gels on glass ionomer and composite restorations. Dent Mater. 1993;9(1):63-67.

14. ABO ENA, Yousef M. Evaluation of Different Restorative Materials after Exposure to Chlorhexidine. J Am Sci. 2012;8(3).

15. Rios D, Honório HM, Francisconi LF, Magalhães AC, Machado MA de AM, Buzalaf MAR. In situ effect of an erosive challenge on different restorative materials and on enamel adjacent to these materials. $J$ Dent. 2008;36(2):152-157.

16. Gürdal P, Akdeniz BG, Hakan Sen B. The effects of mouthrinses on microhardness and colour stability of aesthetic restorative materials. J Oral Rehabil. 2002;29(9):895-901.

17. Weiner R, Millstein P, Hoang E, Marshall $D$. The effect of alcoholic and nonalcoholic mouthwashes on heat-treated composite resin. Oper Dent. 1997;22:249-253.

18. Khan AA, Siddiqui AZ, Mohsin SF, Al-Kheraif AA. Influence of mouth rinses on the surface hardness of dental resin nano-composite. Pak J Med Sci. 2015;31(6):1485.

19. Yap AUJ, Lye KW, Sau CW. Surface characteristics of tooth-colored restoratives polished utilizing different polishing systems. Oper Dent. 1997;22:260-265. 
20. De Moraes RR, Marimon JLM, Jochims Schneider LF, Sinhoreti MAC, Correr-Sobrinho $\mathrm{L}$, Bueno M. Effects of 6 months of aging in water on hardness and surface roughness of two microhybrid dental composites. J Prosthodont. 2008;17(4):323-326.

21. Festuccia MSCC, Garcia L da FR, Cruvinel DR, Pires-De-Souza F de C. Color stability, surface roughness and microhardness of composites submitted to mouthrinsing action. J Appl Oral Sci. 2012;20(2):200-205.

22. Winn DM, Blot WJ, McLaughlin JK, Austin DF, Greenberg RS, Preston-Martin S, et al., Mouthwash use and oral conditions in the risk of oral and pharyngeal cancer. Cancer Res.
1991;51(11):3044-3047.

23. Bolanowski SJ, Gescheider GA, Sutton SVW. Relationship between oral pain and ethanol concentration in mouthrinses. J Periodontal Res. 1995;30(3):192-197.

24. Borrajo JLL, Varela LG, Castro GL, Rodriguez-Nuñez I, Figueroa MG, Torreira MG. Efficacy of Chlorhexidine Mouthrinses With and Without Alcohol: A Clinical Study. J Periodontol. 2002;73(3):317-21.

25. Arweiler NB, Netuschil L, Reich E. Alcohol-free mouthrinse solutions to reduce supragingival plaque regrowth and vitality: A controlled clinical study. J Clin Periodontol. 2001;28(2):168-174. 